\title{
Apoptotic histone modification inhibits nuclear transport by regulating RCC1
}

\section{Chi-Hang Wong, Hei Chan, Chin-Yee Ho, Soak-Kuan Lai, Kheng-Sze Chan, Cheng-Gee Koh and Hoi-Yeung Li}

Nature Cell Biol. 11, 36-45 (2009); published online 7 December 2008; corrected after print 16 December 2008

In the version of this article initially published, the bands showing NF-kB-p50 in Figure 1b, and the columns for GFP and mCherry in Figure 5a were incorrectly labelled. The corrected panels for these fig-

Figure 1

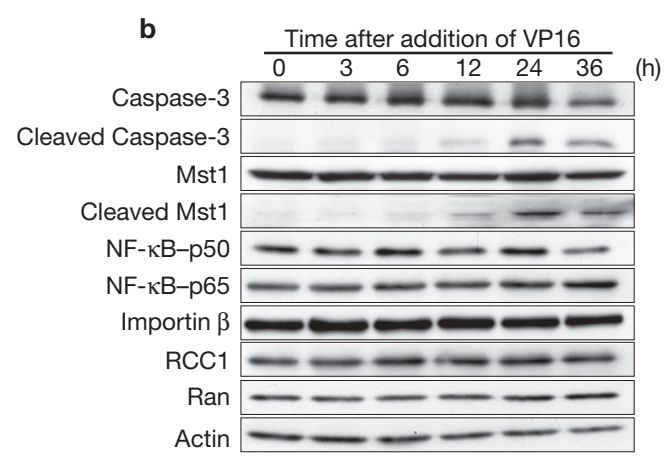

ures are shown below. The Figure $7 \mathrm{~b}$ legend should read “...(15, 5, $2 \mu \mathrm{l})$ " instead of “...(10, $5,2 \mu \mathrm{l})$. These errors have also been corrected in the HTML and PDF versions of the article.
Figure 5

a

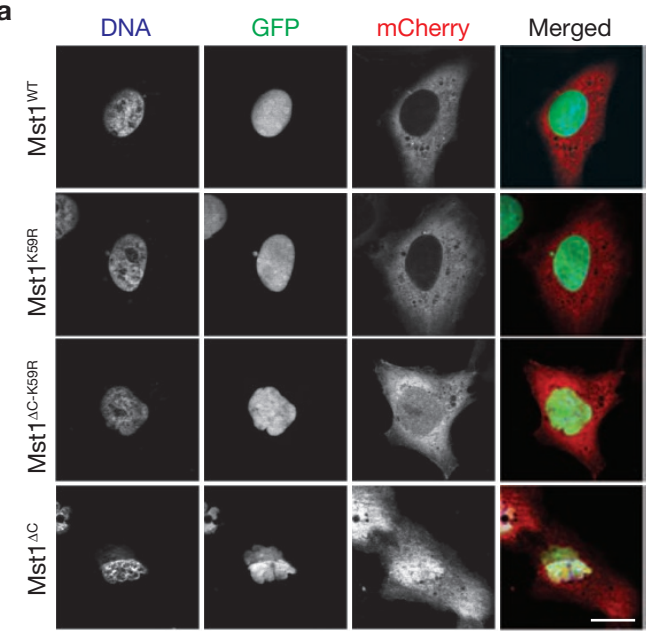

